\title{
Descentralización para la equidad
}

\section{Decentralization towards equity}

\section{Darío I. Restrepo-Botero*}

\begin{abstract}
The processes of decentralization in Latin America are debated between two fundamental forces. One claims the construction of an institutional architecture adapted to the expansion of the neoliberal logic; while other, the socialization of the political, administrative and economic power. Two countries of federal tradition, Mexico and Brazil and two unitary ones, Colombia and Bolivia help to illustrate the transformations realized by virtue of the processes of decentralization and to justify the need of a strategic package of reforms towards the social, political and territorial equity.
\end{abstract}

Keywords: decentralization, Latin America, neoliberalism, socialization of the power.

\section{Resumen}

Los procesos de descentralización en América Latina se debaten entre dos fuerzas fundamentales: una pretende la construcción de una arquitectura institucional adecuada a la expansión de la lógica neoliberal y, la otra, la socialización del poder político, administrativo y económico. Dos países de tradición federal -México y Brasil- y dos unitarios -Colombia y Bolivia- ayudan a ilustrar las transformaciones realizadas en virtud de los procesos de descentralización y a justificar la necesidad de un paquete estratégico de reformas hacia la equidad social, política y territorial.

Palabras clave: descentralización, América Latina, neoliberalismo, socialización del poder.

\footnotetext{
* Universidad Nacional de Colombia, Colombia. Correo-e: direstre@cable.net.co.
} 


\section{Una arquitectura institucional descentralizada para la liberación del mercado ${ }^{1}$}

Los procesos de descentralización no tienen una sola potencialidad ni un solo propósito político. Sus características son el resultado, en cada país, de la pugna entre las principales fuerzas que han intervenido en el rediseño del Estado en las últimas décadas. Por una parte, se reconoce la fuerza de los que Joseph Stiglitz llama los fundamentalistas de mercado (Stiglitz, 2002) y, por la otra, lo que hemos llamado, al igual que otros ensayistas, el surgimiento de nuevas subjetividades democráticas (Restrepo, 2006a). Cada una ha logrado impregnar la realidad de los ajustes territoriales acometidos, aun cuando los resultados alcanzados no terminan por saldar definitivamente la correlación de fuerzas a favor del ordenamiento de la sociedad por el mercado, o por una nueva primacía de los intereses sociales mayoritarios sobre la economía, la política y el poder estatal.

En la estrategia neoliberal los procesos de descentralización impulsan tres dimensiones, cada una de las cuales puede mostrar avances, pero también limitaciones, e incluso efectos contraproducentes para el ajuste del Estado por el mercado. En el terreno económico, se ambiciona disminuir la intervención del Estado en la economía, el gasto público y el profuso número y poder de la burocracia (Wiesner, 1992). Para lograrlos, se debe acometer un ejercicio contable mediante el cual la parte del presupuesto nacional que se gira a las entidades territoriales debe ser menor, o al menos igual, a la empleada por el nivel central de gobierno para los asuntos que se descentralizan. La descentralización como suma cero se considera exitosa si los giros se acompañan de la tercerización o subcontratación de las funciones públicas con el sector privado y, para asuntos de poca complejidad, con organizaciones sociales y solidarias (Burki et al., 1999; вм, 2001). De esta manera se ejecuta política pública con menos funcionaros públicos, al tiempo que se estimula la creación de empresas privadas. También se abaratan los costos de las acciones estatales que se trasladan de manera solidaria a las comunidades beneficiadas por la intervención descentralizada (вм, 1993). Veinte años de experiencias descentralizadoras muestran un aumento del tamaño del Estado, del gasto y de la burocracia estatal, tanto en los ámbitos territoriales como en

${ }^{1}$ La primera versión de las ideas aquí consignadas fueron desarrolladas originalmente en el primer semestre del año 2008, en el marco de una asesoría a la asamblea constituyente de la República del Ecuador, con el apoyo del Instituto Latinoamericano de Investigaciones Sociales (ILDIS) de la fundación Friedrich Ebert en el Ecuador. Después este documento se redactó para el IV Foro Euro Latino Americano Caribeńo de Sociedad Civil, con el apoyo del Centro Peruano de Estudios Sociales (Cepes) y por solicitud del Grupo Propuesta Ciudadana del Perú. Agradezco los comentarios de Enrique Daza, los cuales, sin comprometer sus apreciaciones sobre la materia, mejoraron el texto en claridad y precisión. 
el central. Ante la transferencia de recursos y funciones a los gobiernos locales, la clase política y la burocracia nacional se resisten a ceder poder. Por ello defienden competencias y recursos que les permiten seguir interviniendo en aquellos asuntos descentralizados que debieran haber cedido definitivamente (Castro, 2002). Sin embargo, la estrategia pro mercado se ha servido de la descentralización para avanzar mucho en la subcontratación, en la generación de empresas y en la socialización de los costos de las acciones estatales (Carrión, 2003).

Siguiendo con la dimensión económica, importa señalar que la descentralización es una estrategia para realizar rápidos y legítimos procesos de privatización de empresas estatales territoriales, así como para el alza de tarifas e impuestos. Al transferir funciones con recursos insuficientes para atender los costos de tales competencias y responder a la acrecentada presión social sobre la administración local, los mandatarios, de cualquier filiación política, deben subir tarifas e impuestos, y cuando éstos no alcanzan, endeudarse y privatizar las empresas (Restrepo, 2001). En todos estos terrenos el neoliberalismo puede mostrar resultados, aunque en más de un país el endeudamiento territorial ha sido de tal magnitud que compromete la cartera del sector financiero privado y presiona giros suplementarios del nivel central, lo cual afecta el equilibrio macroeconómico nacional. Es decir, el efecto contrario a lo que se buscaba (Aghón y Edling, 1997; gráficas i y II).

En síntesis, la descentralización es parte de las políticas anticrisis en la medida en que provoca un aumento de las inversiones en infraestructura y servicios, estimula la creación de empresas privadas y sociales, asegura un aumento del crédito público y privado a las entidades territoriales, e incide en los niveles del empleo (Harvey, 2007).

En la dimensión social, la descentralización de las empresas y servicios estatales es un mecanismo eficaz para quebrar la unidad y la fortaleza nacional de los sindicatos de trabajadores del sector público. La localización de los conflictos sociales es un efecto nada despreciable que debiera resultar de la responsabilidad local en asuntos muy sensibles en la calidad de vida de la población. Lo uno y lo otro son activos que puede reclamar el neoliberalismo en América Latina; sin embargo, los conflictos sociales no cesan de rebasar su frontera local, aunque el sindicalismo no logra reponer la fuerza que antaño acumuló de la mano de las grandes empresas estatales de carácter nacional.

Dos grandes propósitos sobresalen en la dimensión política, la despolitización y la fragmentación (Bauman, 1998). Es necesario hacer de la pugna por el poder una confrontación gerencial, convertir la administración local misma en un conglomerado de empresas que compiten, sin favoritismo y monopolio en la recepción y manejo de los subsidios, con otras 


\section{Gráfica I}

\section{Transferencias a entidades territoriales, 1990-2008 (porcentaje PIB)}

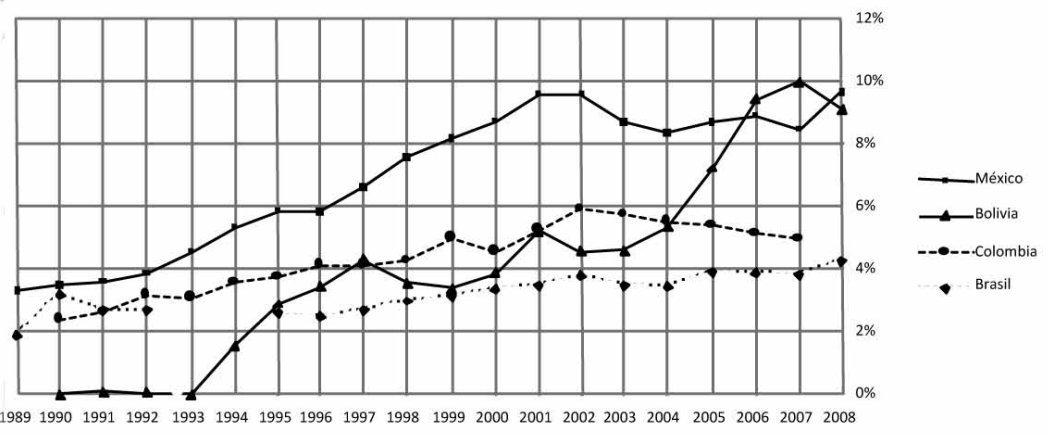

México: pasó de 3.48 en 1990 a 9.64\% en 2008. Fuente: INEGI, Estadísticas públicas estatales y municipales.

Bolivia: pasó de 0.01 en 1990 a 9.10\% en 2008. Fuentes: Federación de Asociaciones Municipales de Bolivia (FAM), Características fiscales y financieras del proceso de descentralización en Bolivia 1994-2008, FMI.

Colombia: pasó de 2.38 en 1990 a 4.94\% en 2007. Fuente: Dirección de Desarrollo Territorial (DNP-DDT).

Brasil: pasó de 1.84 en 1989 a 4.27\% en 2008. Fuente: Banco Central de Brasil, Transferencias a estados y municipios.

Fuente: Elaborada por Diego Acero, Universidad Nacional de Colombia.

\section{Gráfica II}

Comportamiento de la deuda territorial, 1990-2008 (porcentaje de crecimiento respecto al ańo inicial)

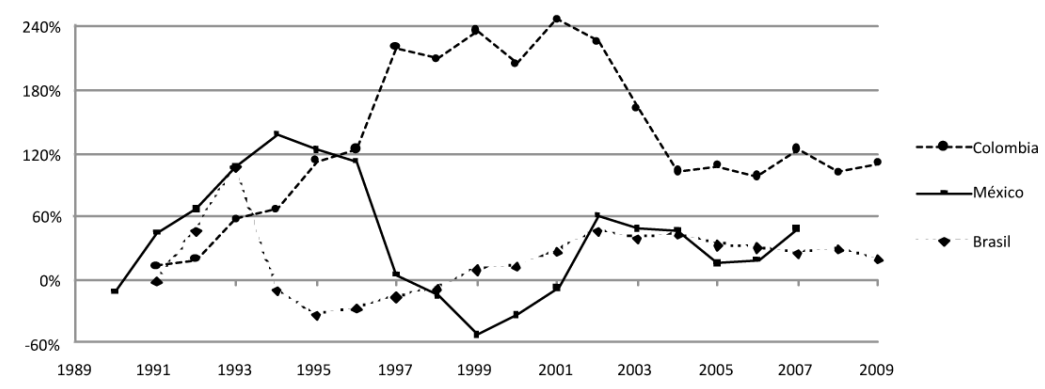

Colombia: en 1991 la deuda territorial creció 12.3\% respecto a 1990, y respecto a este mismo año, en 2009 había crecido 109\%. Fuentes: Ministerio de Hacienda, Banco de la República.

México: en 1990 la deuda territorial decreció 11.7\% respecto a 1989, y respecto a este mismo ańo, en 2007 había crecido 48.5\%. Fuente: INEGI, Estadísticas de finanzas públicas estatales y municipales. Brasil: en 1991 la deuda territorial decreció $1.5 \%$ respecto a 1990 , y respecto a este mismo año, en 2008 había crecido 28.7\%. Fuente: Banco central de Brasil, ipeAdATA, deuda total estados y municipios.

Fuente: Elaborada por Diego Acero, Universidad Nacional de Colombia. 
empresas privadas, en el terreno de la producción y prestación de servicios. Separar la política de la administración, la cual debe manejarse como cualquier empresa competitiva, significa reducir el margen de acción de la política a debates sobre dicotomías morales, como la corrupción, el clientelismo, asuntos de policía y buenas prácticas ciudadanas (Restrepo, 2001).

Continuando en el frente político, si se promueve la responsabilidad de cada ciudadano con los desempeńos de sus mandatarios y gerentes, se construye un poder local consecuente con las realidades de los mercados. Es decir, lograr que a cada mercado local le corresponda un conglomerado poblacional con responsabilidades en la elección, coadministración y control de la red de administradores de empresas públicas. De esta manera se desincentivan las confrontaciones ideológicas sobre la administración, en cambio se estimulan las contiendas gerenciales por resultados de eficiencia y calidad de las unidades prestadoras de servicios (Jessop, 1993). Cada administrador responde por su empresa y cada mandatario por el ambiente general de la red de empresas y servicios, con el fin de aumentar la competitividad del territorio en el mercado. Se obtiene así una fragmentación de la política en cada unidad territorial. Tampoco habría incentivo a la agremiación partidista ideológica en una escala superior, diferente a la de asociaciones de carácter administrativo y de planeación. En otras palabras: construir en cada escala de mercado agremiaciones adecuadas de administración flexible que ejerzan la terciarización.

No existe duda sobre el avance acometido en la dislocación de las agremiaciones políticas supralocales y la profundidad del fenómeno de la personificación de la política: hay más personalidades que partidos políticos y más desempeños de gerencias individuales que comprobación de programas políticos (Eaton, 2004). Las entidades territoriales caen, una a una, en la lucha por la atracción de inversiones públicas y privadas, nacionales y externas, para hacer territorios competitivos, para que así compitan los unos contra los otros, los centrales contra los vecinos, en crear las mejores condiciones para acunar al capital (Rincón et al., 2005).

Esto ha provocado que la gran política y la lucha por asumir las orientaciones que definen los modelos generales de crecimiento y distribución, el reparto de cargas y beneficios en la sociedad y las alianzas internacionales, haya vuelto, una vez más, a mirar hacia la nación. Veinte años de descentralización han servido para revivir el interés por la gran política y la ideología; además, la certeza de que éstas se juegan en lo fundamental mediante la construcción de proyectos mayoritarios en el ámbito nacional. Éste no se puede reconocer como un triunfo del ajuste neoliberal, pero sí un resultado de él (Restrepo, 2006b).

Es frecuente que en las confrontaciones políticas y sociales la dimensión más estratégica no sea de orden material sino cultural, dicho de 
manera más precisa, de cultura política (Melucci, 1999). Para imponer el fundamentalismo de mercado se traspasa la propiedad colectiva, bajo su forma estatal, masivamente a las redes empresariales trasnacionales, y lo que queda de la administración pública se somete a la lógica del mercado, sobre todo mediante la aplicación del principio de libre competencia entre empresas de cualquier naturaleza jurídica. Así queda reunida la condición material para incentivar la cultura del sálvese quien pueda y tenga los medios para ello. Las ciudades poderosas de cada país se tragan sus áreas próximas de influencia y las ponen a orbitar alrededor de sus necesidades, como descongestionar los dormitorios, proveer recursos naturales y alimentos, recibir desechos, dotar de almacenes y relocalizar actividades industriales contaminantes.

Este comportamiento de mezquino agujero negro se distancia de los principios de solidaridad, sin duda imperfectos, que construyeron los Estados nacionales durante el siglo xx (Ocampo, 2002). No sorprende que las élites políticas de las grandes ciudades se quejen de aportar la mayor cantidad de recursos tributarios al presupuesto general para que se distribuya a otras zonas, caracterizadas por sus incapacidades emprendedoras, subdesarrollo institucional y pereza fiscal. La justicia de mercado es contraria al principio de redistribución, a cambio del cual levanta a aquél de la retribución: la lógica es premiar al ganador en un mundo donde impera la competencia. Tales voces se oyen desde Bogotá, pasan por Guayaquil y Quito y aturden en Santa Cruz de la Sierra. Cada cual debe recibir en proporción directa a su capacidad y no en relación con sus necesidades. Para asegurar este principio de justicia nada mejor que un radical estatuto de autonomía tributaria, entendido como el quiebre de las finanzas nacionales y la concentración de los medios económicos de las grandes urbes en manos privadas (Molina, 2008). Los otros territorios son zonas reservadas para continuar el colonialismo interno, es decir, la succión de sus recursos naturales, agropecuarios, mineros, de hidrocarburos, el agua y los bosques.

¡Abajo el Estado paternalista, viva la ideología de la responsabilidad de cada uno ante lo suyo! Superada debe quedar la larga época en que a cada necesidad de gran sensibilidad social debiera seguirle su conversión en derecho político ciudadano y obligación estatal. Ahora asistimos al reino de la solidaridad de mercado. Toda proclama y reivindicación debe abandonar la pugna propia de comportamientos inmaduros y antisociales, contrarios a los derechos humanos, a los derechos de los otros. A cambio, las necesidades y derechos deben convertirse en proyectos, promovidos por empresas sociales, que compitan por hacerse de los contratos de las bolsas estatales, privadas y de la filantropía internacional (Cortés et al., 2002). Las protestas deben mutar en proyectos, las reivindicaciones 
en contratos, la pugna en sociedad mercantil, las organizaciones populares en empresas sociales, la política en gestión y el Estado en mercado.

La descentralización en la cosmogonía neoliberal no es entonces una dádiva a los movimientos sociales y a los reformistas demócratas, tampoco ocupa un lugar marginal en su acervo programático; por el contario, la descentralización hace parte de las reformas espaciales impulsadas por el neoliberalismo con la pretensión de reestructurar el conjunto de las relaciones económicas, políticas, sociales e ideológicas (Moncayo, 1990; Pradilla, 2010).

\section{Descentralizar para socializar el poder}

La lucha contra los regímenes autoritarios latinoamericanos durante los años setenta y ochenta derrumbó las hegemonías militares y desprestigió las democracias restringidas del continente, como la colombiana y la mexicana. Lo que no se observó al comienzo fue la enorme ola de subjetividades políticas que coincidieron en el repudio a la estrechez de los sistemas representativos. No se trató exclusivamente de aspirar a un retorno de las formas y prácticas de la democracia liberal clásica: pluripartidismo, separación de poderes, derechos de oposición; sino también de rebasar los limitados márgenes de los sistemas representativos en los Estados centralizados liberales. Los reclamos de descentralización política y de participación ciudadana y comunitaria en los más diversos asuntos públicos surgieron con fuerza inusitada. El reconocimiento de los derechos de representación política a las fuerzas sociales marginadas de siempre: asalariados, campesinos, viviendistas; se combinó con la pugna por la representación de nuevos sectores urbanos, cívicos y de mujeres, principalmente (Cortés et al., 2002). La realidad política latinoamericana es hoy, veinte años después, tributaria de esa fuerza emergente que todavía no cesa de irrumpir en la escena, reclamando más cantidad, capacidad y calidad de su representación política.

Un líder obrero llegó a la presidencia en Brasil; después de 500 años el primer presidente indígena de América gobierna Bolivia; un militar nacionalista está a la cabeza de una potencia petrolera caribeńa, la República Bolivariana de Venezuela; un académico ligado a las organizaciones no gubernamentales gobierna el Ecuador y un ex obispo progresista recién llega a ocupar la silla de primer mandatario en Paraguay. Obreros, indígenas, campesinos, religiosos, socialistas, nacionalistas... América Latina está irreconocible. El recuento sería muy extenso si la mirada se posara en los cargos en los niveles intermedios y locales. La apertura de los sistemas políticos a la representación de las fuerzas marginadas y cuyos anhelos fueron postergados, cuando no reprimidos, en las décadas de los 
sesenta, setenta y ochenta, es un hecho palpable. Más allá de la gran representación, se encuentra un número exponencialmente mayor de ciudadanos, comunidades, sectores y organizaciones sociales que empujan las puertas de las burocracias e invaden a través de espacios estatales antes reservados al monopolio de políticos y funcionarios profesionales. La paradoja de tal apertura política es la tentación del caudillismo, el mesianismo y el autoritarismo popular por arriba y por abajo, la fragmentación social mediante una miríada de microgestiones forjadas desde las múltiples expresiones de un cierto individualismo comunitario (Restrepo, 2006b).

Más allá de la dupla dicotómica: estatismo-colectivismo o liberalismoindividualismo, las nuevas prácticas políticas batallan por introducir un nuevo paradigma: la socialización del poder. No se trata sólo de la elección popular de alcaldes y gobernadores, sino de la construcción de mandatos populares durante la campaña electoral; no es suficiente conocer las intenciones de los gobernantes, ahora muchos aspiran a definir planes y presupuestos participativos; además del derecho a la alternancia partidista una vez concluido el periodo de gobierno, se reclama la posibilidad de revocatoria de los mandatos por incumplimiento de los programas de gobierno; es creciente la exigencia de gestiones honestas, para cuya garantía se presionan rendiciones públicas de cuentas de la administración y el Poder Ejecutivo; se aspira a incrementos en la calidad y eficiencia de la administración y los servicios públicos, para cuyo fin la participación ciudadana y comunitaria en las instancias y programas públicos tiene una importancia definitiva.

¿Cuál es la relación entre prácticas participativas y ordenamiento espacial del Estado? En teoría no existe una relación unívoca. Un régimen centralista puede fomentar masivos ejercicios de participación o negarlos; así como una estructura descentralizada, y los gobiernos locales pueden asentarse con base en prácticas paternalistas y autoritarias, o ser el resultado vivo de un empoderamiento ciudadano sobre la administración pública (Toranzo, 1999). Sin embargo, en la América Latina de los años ochenta, noventa y todavía a principios del siglo XXI, movimientos sociales -en particular los étnicos, de base rural y cívica- identifican la construcción de su poder con la participación social en formas descentralizadas de gobierno (Fals, 2000). La reivindicación de autonomía territorial no se vive como reclamo de autismo y segregación, sino como apropiación a escala local del poder político, administrativo y económico. Sabido es que la exigencia de autonomía territorial no es patrimonio de una exclusiva intención estratégica. Por el contrario, está en las entrañas mismas de la lógica de la competencia de las regiones ganadoras contra las perdedoras, del sector privado transnacionalizado contra las cargas del Estadonación, del colonialismo interno, y de la versión contemporánea del de- 
sarrollo desigual y combinado del capitalismo de enclave. Por lo anterior valen dos advertencias: la primera invita a romper la relación unívoca entre las exigencias de descentralización con la democracia y el desarrollo equitativo entre regiones internas; y la segunda asegura la absoluta necesidad de la dimensión nacional e internacional en la profundización de prácticas y sistemas democráticos, incluso de los locales (Castagna et al., 2002).

La socialización del poder político y de la administración se extiende también hacia un reclamo por socializar el bienestar y el poder económico. En el ideario de los movimientos populares de las últimas décadas en América Latina se encuentra la lucha por el acceso a bienes esenciales, como salud, educación, agua potable, transporte, vivienda digna, servicios públicos y justicia (Seoane et al., 2006).

Estas exigencias contradicen el natural destino de las inversiones que proclama el neoliberalismo para los bastiones geográficos y sociales ganadores del desarrollo (Restrepo, 2003). Contrariedad mayor generan los movimientos sociales y las fuerzas políticas que obligan la relocalización irracional de inversiones para apoyar mercados, regiones y poblados deprimidos. La descentralización del modelo de desarrollo contradice el carácter de enclave del Estado y del desarrollo. Una advertencia, no se trata de una mera reivindicación de inversiones en los territorios subdesarrollados, debido a que éstas pueden tener la intención exclusiva de extraer los recursos naturales, energéticos y medioambientales de las regiones. La creación de sistemas económicos locales supone la retención territorial del excedente, es decir, algo totalmente contrario a la doctrina del liberalismo económico que se opone a toda regulación que cohíba la plena libertad de movilidad espacial del capital (Benko y Lipietz, 1994).

Sin embargo, el alcance de los procesos de descentralización se limita a la política social y los asuntos de infraestructura, turismo y agropecuarios de baja complejidad. Todavía no se logran desconcentrar los factores decisivos del crecimiento y la redistribución económica: propiedad, industrialización, gran infraestructura, ciencia y tecnología, crédito y tributación, principalmente (Misas et al., 2005). Las brechas en los índices de desarrollo entre entidades territoriales se han profundizado desde la década de los setenta (Ocampo, 2002). Más aún, a pesar de una difusión de los sistemas políticos, del gasto público y de la presencia estatal en los territorios - de la mano de la descentralización-, el poder económico y político, privado y estatal, todavía sigue muy concentrado social y territorialmente (Restrepo, 2007b). 


\section{Finanzas territoriales y equidad}

Dos fuerzas antagónicas se disputan la redefinición del ordenamiento territorial de los Estados en América Latina. No se trata de una confrontación entre centralistas y descentralistas, sino de una pugna por la primacía social y política en cualquiera de las prioridades de organización espacial del Estado (Restrepo, 2001). Aquí hemos sustentado como signo de distinción de la fisura estratégica la primacía por la privatización o la socialización del Estado, las rentas públicas y la lógica política. En lo que queda invitamos a considerar una serie de propuestas a la descentralización ordenadas a partir de la lucha por la equidad y la socialización del poder. Este esfuerzo tiene sentido únicamente si la izquierda democrática en América Latina considera que el ordenamiento espacial interno permite obtener fines mayores en la construcción de la equidad, el bienestar y la democracia (Montañés, 2001). Si por el contrario, la amenaza de la globalización neoliberal recomienda, bajo ciertas condiciones, limitar la autonomía de los espacios territoriales y fortalecer el eje del poder central, entonces lo que sigue carece de pertinencia o, al menos, de actualidad o urgencia. La apuesta de este trabajo es ilustrar los márgenes de ganancia que cierto manejo de la lógica espacial podría aportar a la construcción del poder interno, el cual debe, a toda luces, complementarse con un acuerdo mayoritario sobre las prioridades políticas nacionales y con la construcción de alianzas internacionales, en particular apretar el paso de la integración económica, institucional y monetaria de América Latina. ¿Qué tiene que ver la integración con la descentralización? A nuestro entender, mucho (Torres et al., 2005). Pero explicar esta relación excede el propósito de este ensayo. Nos limitamos a señalar que son las dos principales dimensiones de transformación espacial de los Estados nacionales. En este contexto, advertir que una integración carente de un propósito explícito de apoyar el desarrollo de las regiones más marginadas en cada país puede aumentar aún más la concentración del desarrollo. Así, se acrecentarían las diferencias en los niveles de bienestar y, por tanto, se ensancharían las inequidades internas. La otra amenaza a considerar es la intensificación de procesos de descentralización carentes de un marco mayor de integración supraestatal. Tal situación puede conducir a frágiles unidades administrativas territoriales a negociar en condiciones muy precarias con el mercado mundial. Al final, se debilitarían los mecanismos de solidaridad interna de las naciones, se comprometería la estabilidad de los sistemas estatales y se podría caer en una guerra fiscal entre entidades territoriales (Carreras et al., 2005).

Hechas estas advertencias, pasemos entonces a las propuestas. No deja de sorprender que el pensamiento crítico latinoamericano se entretenga 
en la discusión sobre los usos que se dan a la distribución territorial de los recursos de los presupuestos nacionales, buscando con ello rivalizar o, al menos, volver compatible la prelación por la eficiencia, con aquella por la equidad. Así, olvida trabajar los dos lados de la ecuación de toda discusión sobre equidad en el gasto público: quienes aportan a la financiación del Estado y quienes se benefician del gasto público. En los dos lados de la ecuación debe imperar un claro criterio de equidad, so pena de correr grandes riesgos contra la justicia social o, por lo menos, desperdiciar una gran oportunidad para hacer de los giros un instrumento claro de redistribución de recursos en la sociedad. Cualquiera que sea el origen de los recursos y los criterios de asignación del gasto, siempre nos toparemos con consecuencias más o menos claras o indirectas con la equidad.

$\mathrm{Si}$, por ejemplo, los recursos provienen en lo fundamental del crédito externo, se evita la financiación por la vía del presupuesto regular del Estado y, con ello, la discusión sobre la proporción de los aportes de diferentes grupos sociales y actividades económicas. Además, la sostenibilidad del gasto descentralizado se encontraría fácilmente comprometida. Inscribir los giros como porcentaje -fijo, creciente o condicionado- del presupuesto nacional le otorga diferentes niveles de certeza al gasto público descentralizado, pero no resuelve la duda sobre la contribución de la financiación a la justicia redistributiva. En la mayoría de los casos se giran porcentajes del presupuesto general, o del gasto público social o de una bolsa específica de impuestos. Sin embargo, poca claridad existe sobre el esfuerzo social relativo en la constitución de esas fuentes. Si nos atenemos a la tendencia general de la tributación en la región, con ciertas y notorias excepciones, los impuestos más dinámicos son aquellos que representan una carga mayor a las clases bajas y medias de la población, respecto de los ingresos relativos de los diferentes niveles sociales. Es decir, los impuestos indirectos y el trabajo formal retiran de los sectores populares y medios porcentajes mayores del total de ingresos de esta población. En cambio, los impuestos directos a la riqueza y la propiedad representan porcentajes menores respecto de los recursos totales de las clases altas. Así las cosas, los recursos cedidos de la nación a las entidades territoriales podrían estar viniendo, indirectamente, de la base de la pirámide social... con destino a financiar la política social de esas mismas clases. En este caso se trataría, cuando más, de una redistribución intraclase.

Para lograr una relación más clara entre la financiación de las políticas territoriales y la equidad, se propone crear un sistema que relacione el origen del ingreso con el destino del gasto, por ejemplo, de la siguiente forma. Por el lado de los ingresos, mediante un porcentaje directamente proporcional al producto interno bruto per cápita de los niveles territoriales intermedios y las grandes ciudades, otro porcentaje del impuesto a 
la riqueza y, otro tanto, de los tributos y tasas al consumo, finalmente, un monto fijo por entidad territorial. De esta manera las entidades territoriales de mayor desarrollo, las clases sociales más pudientes, los más asiduos consumidores y cada entidad territorial contribuirían de manera proporcional a su riqueza. Por el lado del gasto, se aplicaría el criterio inverso: se recibiría una mayor porción de la bolsa a menor producto interno bruto territorial, mayor cantidad de pobreza total y relativa, más precario desarrollo institucional relativo y menor capacidad fiscal (gráfica III). Una advertencia: la experiencia de los últimos años enseña que privilegiar con mayor gasto público situaciones de precariedad puede convertirse en un estímulo perverso a no superar la pobreza y el subdesarrollo (Nueva Sociedad, 2008). Por tanto, es prudente introducir un criterio de eficiencia precisamente a los giros: de eficiencia en la reducción de las precariedades. Por ejemplo, las mejorías en el esfuerzo fiscal relativo, las disminuciones en los niveles de pobreza y la reducción de brechas de inequidad deberían ser entusiastamente premiadas.

\section{El presupuesto nacional y la equidad en la financiación territorial}

Muchos de los movimientos sociales periféricos pugnan por una descentralización del gasto público (Seoane et al., 2006). Por ello los sectores progresistas asocian la descentralización con una mejor distribución territorial y social del gasto público, es decir, con la equidad. Esta pugna nos advierte sobre la necesidad de volver la mirada a la distribución general de los recursos presupuestales de un país. El presupuesto es quizás el arma más poderosa para impulsar la integración de las economías, el desarrollo más equilibrado entre las regiones y la redistribución social de oportunidades y riquezas producidas. O podría llegar a serlo. Además de contener una parte general sobre el gasto asignado a instituciones y funciones netamente centrales, los presupuestos nacionales debieran organizarse de manera espacial; es decir, ser absolutamente claros en señalar el destino territorial de los gastos que hoy aparecen como si fueran generales y sectoriales, omitiendo indicar las entidades territoriales receptoras de dichas erogaciones. No se pretende someter el presupuesto nacional, ni ningún otro, a un mero principio de igualdad: todos reciben igual cantidad de recursos, servicios, atenciones, reconocimientos o apoyos. La propuesta no es acercarse al igualitarismo, sino a la equidad. Una formulación adecuada de equidad podría ser: Cada uno aporta en proporción a sus capacidades y recibe en relación con sus necesidades y el esfuerzo relativo que realice. La ventaja de la organización territorial del presupuesto nacional es la obligación de un debate sobre los criterios de asignación de 


\section{Gráfica III \\ Concentración geográfica del PIB, 1990-2007 (territorios principales)}

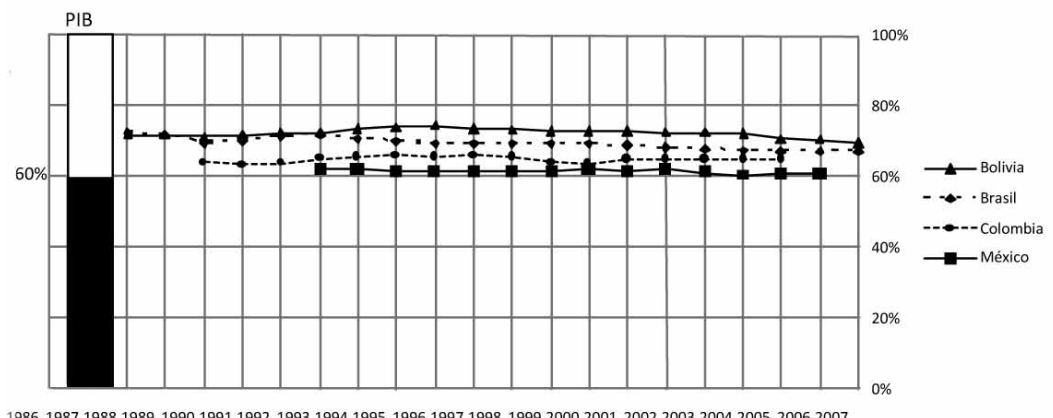

1986198719881989199019911992199319941995199619971998199920002001200220032004200520062007

Bolivia: tres de nueve departamentos, La Paz, Santa Cruz y Cochabamba, pasaron de concentrar 71.4\% del pIв en 1990 a 69.6\% en 2007. Fuente: Instituto Nacional de Estadística.

Brasil: cinco de 27 unidades federativas, São Paulo, Río de Janeiro, Minas Gerăis, Rio Grande do Sul y Paraná, pasaron de concentrar 69.3\% del pib en 1990 a 66.8\% en 2007. Fuente: IBGE, Departamento de Cuentas Nacionales.

Colombia: el distrito capital y cinco de 32 departamentos, Bogotá D.C., Antioquia, Valle, Cundinamarca, Santander y Atlántico, pasaron de concentrar 63.8\% del piB en 1990 a 64.7\% en 2005. Fuente: DANE, cuentas regionales.

México: ocho de 32 entidades fedetarivas, Distrito Federal, Estado de México, Jalisco, Nuevo León, Veracruz, Guanajuato, Puebla y Chihuahua, pasaron de concentrar 62.2\% del PIB en 1993 a 60.7\% en 2006. Fuente: INEGI, Sistema de Cuentas Nacionales.

Fuente: Elaborada por Diego Acero, Universidad Nacional de Colombia.

los recursos: el desarrollo relativo, la pobreza, las necesidades de infraestructura, el estímulo a sistemas económicos territoriales, la generación de conocimiento, ciencia y tecnología apropiada, la conservación productiva del medio ambiente, el agua y los bosques, e inversiones en vivienda, educación y salud.

\section{Una sola bolsa para la financiación de planes territoriales de desarrollo}

También ganaría claridad el debate público si se conforma una sola contabilidad con el conjunto de mecanismos de financiación de las políticas territoriales; muchos de los cuales obedecen a lógicas de asignación diferentes y, en conjunto, no cumplen un criterio de redistribución equitativa de oportunidades entre los territorios de la nación. Unos son los criterios de giros obligados por las constituciones y las leyes a los gobiernos locales, los cuales cubren a todas las entidades territoriales y se ordenan a partir de reglas de cálculo sabidas. Otros son aquellos que poseen un carácter circunstancial a cargo del crédito externo y dependientes de las presidencias 
de las repúblicas, los cuales privilegian a grupos de población y territorios específicos. Un tercer paquete de recursos se genera a partir de los reconocimientos que varios países hacen a las entidades territoriales por la explotación de recursos no renovables, los cuales premian con asignaciones los lugares donde el azar situó el bien natural. Finalmente, también existen importantes gastos a cargo de los diferentes sectores administrativos y económicos, los cuales son sensibles a las relaciones políticas establecidas entre los líderes locales y las mayorías políticas nacionales.

El presupuesto nacional debiera ser instrumento para el desarrollo más equitativo entre las regiones. Para que así sea, es deseable que los giros se subordinen a planes de desarrollo territoriales, que hayan cursado obligatoriamente un intenso proceso de participación y concertación local en las prioridades del desarrollo. Hacia el mismo fin abogan fondos de compensación interregionales que, a la vez que compensen diferenciales en niveles y capacidades de desarrollo, se especialicen en el emprendimiento de proyectos de integración regional.

Pero quizás el reto más grande sea lograr que el presupuesto nacional tenga un verdadero carácter nacional, es decir, que la matriz central de su formulación sea la preocupación por la distribución de oportunidades de desarrollo en todas las regiones y, en consecuencia, el apoyo a las prelaciones locales de desarrollo (DNP, 2003). Si así fuera, se convertiría en un poderoso instrumento de integración nacional y de equidad, en lugar de ser como hasta ahora de manera predominante: la organización de la hegemonía de sectores económicos y territoriales dominantes. El proceso de ejecución del presupuesto podría combinar cuatro principios: primero, el acuerdo sobre las prioridades nacionales, estado de conciencia al cual se llega como resultado de una amplia participación de representantes de todos los territorios en su discusión y aprobación; segundo, la concurrencia obligatoria de todos los niveles de gobierno en la implementación de las políticas nacionales estratégicas; tercero, el derecho de cada territorio a establecer prioridades y perfiles de desarrollo propios, y cuarto, el apoyo de la nación a la financiación y ejecución de las prioridades territoriales.

\section{Recoger y volver a repartir tributos y rentas}

Característica de todos los estados latinoamericanos, sean unitarios o federales, ha sido la concentración tributaria en el nivel central de gobierno. Desde los años veinte y treinta del siglo $\mathrm{xx}$, los más importantes impuestos y tasas creadas fueron para alimentar la capacidad de la nación de emprender, desde el Estado central, estrategias de desarrollo del mercado: construcción de puertos y carreteras, sistema bancario y de crédito, 
empresas comerciales, productivas y de servicios, incentivos para el desarrollo económico sectorial y selectivo. Gracias a la centralización de la fiscalidad se financió el Estado-nación latinoamericano. Los tributos territoriales quedaron rezagados ante la dinámica nacional (Eaton, 2004). Sin embargo, desde las décadas de los sesenta y setenta la mayoría de Estados combinaron un renovado interés por la financiación del desarrollo regional para ampliar el mercado nacional, con reformas tributarias para acrecentar la capacidad fiscal territorial (Aghón, 2001). Posteriormente, una característica distintiva de los procesos de descentralización, desde la década del ochenta, fue precisamente el incremento del esfuerzo nacional para financiar sectores de política social descentralizados, además de otras funciones consideradas connaturales a los niveles locales de gobierno. Al tiempo ha aumentado la presión para que los niveles subnacionales aumenten, por su parte, el esfuerzo fiscal propio. Si bien la fiscalidad local es hoy más dinámica y contribuye a asumir las competencias cedidas y a costear la administración, la mayoría de los gobiernos locales de América Latina se mantienen con las transferencias de la nación. A esta situación se le conoce técnicamente como dependencia fiscal. No podría ser de otra manera. El atraso en los grados de desarrollo, en la capacidad institucional y, por tanto, en la fiscalidad, son el resultado producido por el Estado y el mercado de enclave en la mayoría de entidades territoriales. Expresión de lo mismo es el recaudo de las principales fuentes fiscales por el nivel nacional. Sin duda los gobiernos locales pueden y deben acometer un mayor esfuerzo por incrementar sus tributos. Mucho hay por hacer contra la evasión y la elusión que resultan de la combinación entre un bajo desarrollo institucional y la fusión entre la clase política local con las élites económicas lugareñas.

Pero, de cara a equilibrar capacidades de desarrollo y bienestar en todos los territorios internos, se impone también considerar un nuevo pacto fiscal que distribuya mayores recursos. Incluso, tal reparto puede ser concebido como parte de una estrategia para ampliar capacidad fiscal local. En pocas palabras: Si existe dependencia fiscal es porque hay centralización de la fiscalidad, y si se quiere aumentar la autonomía fiscal local se impone una reforma al sistema tributario que equilibre la disponibilidad de recursos entre niveles de gobierno.

El segundo componente que ayudó a financiar la ampliación del Estado fueron grandes empresas, en general de extracción minera e hidrocarburos, de transporte y telecomunicaciones, y del sector financiero. Algunas veces fueron directamente creadas por el Estado, otras nacionalizadas al sector privado, pero siempre se mantuvieron las principales rentas fiscales a cargo del Estado central. El sello inconfundible del neoliberalismo ha sido la privatización del máximo de activos estatales. La 


\section{Gráfica IV \\ Crecimiento de ingresos territoriales propios (porcentaje respecto al año inicial)}

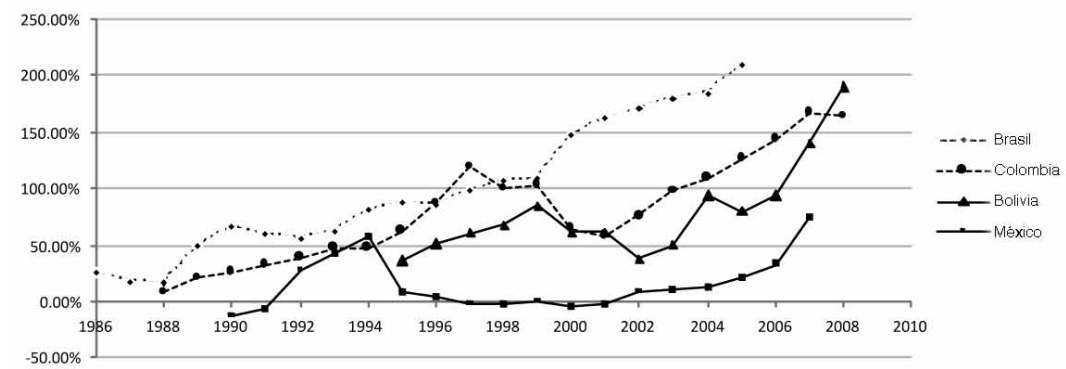

El porcentaje de crecimiento se calcula en valores constantes respecto al ańo inicial de cada serie. Brasil: en 1986 los ingresos territoriales propios crecieron 24\% respecto a 1985, y respecto a este mismo ańo, en 2005 habían crecido 208\%. Fuente: Presidencia de la República Federativa de Brasil. Colombia: incluye $44.7 \%$ de los municipios y el total de los departamentos. En 1988 los ingresos territoriales propios crecieron 7.8\% respecto a 1987, y respecto a ese mismo ańo, en 2008 habían crecido 164\%. Fuente: Banco de la República.

Bolivia: en 1995 los ingresos territoriales propios crecieron 35.9\% respecto a 1994, y respecto a este mismo año, en 2008 habían crecido 189.8\%. Fuente: Federación de Asociaciones Municipales de Bolivia.

México: en 1990 los ingresos territoriales propios decrecieron 12\% respecto a 1989, y respecto a este mismo año, en 2007 habían crecido 74\%. Fuente: INEGI, Estadísticas de finanzas públicas estatales y municipales.

Fuente: Elaborada por Diego Acero, Universidad Nacional de Colombia.

propiedad de empresas productivas, comerciales, de servicios y financieras ha cambiado de manos. En algunos países se discute, e incluso se reclama con alevosía, el derecho territorial sobre la propiedad, el manejo, las rentas y los tributos de empresas y recursos naturales estratégicos, como los mineros y los hidrocarburos; y mañana, con seguridad, de los recursos naturales esenciales para la vida como las grandes fuentes de agua y los bosques (Molina, 2008). A nuestro parecer, nada entraña más riesgo para la explosión de los Estados y alienta la confrontación interna en las naciones, que arrebatar la propiedad o las rentas fiscales de los sectores estratégicos al nivel central del Estado. El llamado a la autonomía tributaria y estratégica posee en este caso el claro tufillo de la segregación y de la ruina del Estado-nación, a favor de poderosos intereses territoriales vinculados a las redes económicas globales manejadas por los conglomerados multinacionales.

Asunto diferente y no menos acuciante es discutir el uso de regalías, rentas e impuestos derivados de la explotación de recursos naturales no renovables. La mayoría de las veces tales recursos se encuentran separados de los centros urbanos e industriales, en regiones que reciben compensa- 
ciones propias del Estado y el mercado de enclave. Es decir, con frecuencia no incentivan la generación de sistemas económicos locales, debido a que no retienen excedentes económicos y tecnológicos suficientes para fecundar el desarrollo regional (Becker et al., 2004). Se debe explorar una mayor participación de los territorios en las complejas decisiones de cómo estimular el desarrollo sostenible cuando se depende de manera abrumadora de un recurso natural escaso.

\section{Descentralización y soberanía ciudadana y popular}

Una característica de la época es la gran desconfianza hacia la democracia representativa, en particular con los poderes legislativos en todos los ámbitos y con los partidos políticos. Es difícil no reconocer en dicho desprestigio la causa de la gigantesca popularidad y expectativa con los mecanismos de participación ciudadana y comunitaria en las políticas públicas (Carrión, 2003). Bien sea en la ejecución de proyectos, el control de la administración pública, la decisión popular en prioridades de los planes y presupuestos locales, y las demandas de transparencia y lucha contra la corrupción. Sin embargo, las prácticas participativas no son suficientes para reemplazar la agremiación y sentido político que ejercen partidos y órganos de representación. Con la intención de aumentar la calidad de la democracia, las prácticas representativas ganarían mucho si incorporaran en su ejercicio cotidiano procesos participativos. Por ejemplo de tres maneras: en la elaboración de programas con amplia participación de diferentes sectores, la selección de los candidatos a través de consultas populares y la rendición de cuentas de los representantes a sus bases políticas.

En todo caso, la participación directa de millones de personas ha ganado un reconocimiento propio en la medida que ha forzado buena parte de los procesos constituyentes en América Latina. Además, a la intervención directa de campesinos, trabajadores, comunidades étnicas, movimientos cívicos urbanos y regionales, a las mujeres y luchadores por los derechos humanos, se les reconoce buena parte de la extensión de la frontera de los derechos sociales, políticos, culturales y étnicos en las últimas décadas.

En el ámbito territorial, la experiencia más interesante de incidencia social en la administración pública se encuentra en los planes y presupuestos participativos (Sousa, 2003). De igual importancia son los mandatos populares en tanto compromisos públicos de los candidatos con plataformas construidas mediante procesos de participación. La revocatoria de los mandatos, cuando el elegido incumple de manera flagrante sus compromisos, sería una consecuencia terminal de la soberanía popu- 
lar participativa en toda la cadena de la democracia representativa. Sin embargo, se debe admitir que esta práctica, aunque gana espacio de reconocimiento constitucional y legal en varios países, ha tenido muy poca efectividad. Mayor despliegue ha tenido la participación en el control a la gestión pública, cuya expresión más avanzada supera el concepto de control sancionatorio y se eleva al de las evaluaciones participativas rutinarias y estratégicas. Es decir, hacia la construcción de una ciudadanía activa que afecta directamente la construcción, implementación, evaluación y revisión de prioridades de política y gasto público. Se trata sin duda de una tendencia hacia la socialización de la administración, el gasto y las políticas públicas, mediante la apertura de instancias de participación en entidades y procesos decisorios, así como con la afectación de la planeación, los presupuestos y proyectos específicos.

\section{Lucha contra la pobreza o reducción de la inequidad}

La reducción de la pobreza y de la inequidad no son procesos equiparables en todos los casos (Restrepo, 2007a). La pobreza se trata como una situación, un estado de cosas, un conjunto de carencias en que a cada una se le establece una medida a partir de la cual se puede superar. Por eso se habla de línea de pobreza e índice de necesidades básicas insatisfechas. Una persona es miserable si dispone de menos de un dólar al día, y pobre si no tiene más de dos. De la misma manera, se es pobre cuando el piso del hogar tiene ciertas características, se carece de ciertos niveles de escolaridad y los ingresos alcanzan sólo para comprar una porción incompleta de la canasta básica necesaria para encontrarse mínimamente nutrido.

La equidad es un término que invoca una relación entre grupos sociales, los cuales en virtud de características derivadas de su posición social unos obtienen ventajas y otros desventajas, para hacer valer sus derechos y gozar de oportunidades. Por ejemplo, algunos habitantes de las ciudades acceden con cierta facilidad a los servicios de salud, mientras para la mayoría de la población rural latinoamericana los centros de salud son inalcanzables. En las urbes, la atención de calidad se concentra también alrededor de los barrios de estratos altos y medios, mientras se alejan de los sectores marginales. Unos regímenes de salud reconocen ciertas enfermedades y permiten ordenar medicamentos en consecuencia, mientras otros restringen el derecho a contraer enfermedades relativamente comunes y masivas dentro de los sectores populares. El sector informal, es decir, más de la mitad de los trabajadores latinoamericanos no conocen la seguridad en los ingresos, se les está negado un salario mínimo legal, no poseen contratos de trabajo, por lo que no acceden a la seguridad social y son presa fácil de la asistencia pública y privada clientelista. Las 
niñas asisten menos a la escuela que los niños, cursan menos años y padecen mayores grados de deserción. El crédito, incluso el manejado por entidades estatales, se concentra en una porción bastante pequeña de la población. Las condiciones de salubridad, seguridad y calidad de la infraestructura son muy desiguales según el barrio en el que se vive. Sabido es que, a pesar de enormes esfuerzos, las mujeres sufren mayores dificultades que los hombres para ascender en los cargos públicos y, además, por idéntico trabajo no se les reconocen similares salarios. $Y$ así sucesivamente... La inequidad se genera cuando la sociedad reproduce mecanismos de discriminación que terminan por negar selectivamente los derechos a los trabajadores, los pobres, los indios, los negros, las mujeres, los barrios marginales, a la población rural y analfabeta (gráficas V-VIII).

Es necesario constatar dos cosas: primero, que no toda inequidad se da contra los pobres, aunque es evidente que éstos sufren las mayores vejaciones y violencia contra sus derechos fundamentales y la dignidad de las personas; en segundo lugar, que no toda reducción de la pobreza necesariamente significa una disminución de las inequidades. Más aún, en muchos países de América Latina se ha reducido la pobreza al tiempo que aumenta la concentración del ingreso, el crédito y los privilegios tributarios en pequeńos círculos privilegiados. La mayoría de los programas de lucha contra la pobreza, adscritos a las presidencias de las repúblicas, cultivan la dependencia del beneficiario respecto de los políticos y la burocracia que administra los programas. El beneficiario es presa fácil del nepotismo, la corrupción, el favoritismo y de los traficantes de la pobreza. En las últimas décadas, la lucha contra la pobreza ha sido un instrumento fundamental en la legitimación de prácticas autoritarias y el mesianismo (Rodríguez, 2002). Por el contrario, cuando la sociedad reduce brechas de inequidad fortalece los derechos de la población que carecía de ellos, equilibra relaciones de poder entre grupos, aumenta las oportunidades de autodeterminación y, por tanto, acrecienta la dignidad de grupos y personas. Una sociedad más equitativa construye condiciones de posibilidad para una mejor democracia, una mayor difusión de oportunidades de participación en la definición de los fines de la política pública y la administración de los bienes colectivos.

Es necesario optar por la equidad, no en oposición al objetivo inaplazable de acabar con la pobreza, sino integrándola en una perspectiva hacia el alcance de la democracia social y política. Pero entonces, ¿̨cómo avanzar hacia la equidad? La ejecución de política social es un camino en esta marcha. Abandonar una focalización del gasto que discrimina entre la población igualmente vulnerada en sus derechos, que prefiere los subsidios parciales, el gasto ocasional, aleatorio y supeditado a decisiones presas del clientelismo. Propender, por el contrario, por una cobertura 


\section{Gráfica V \\ Bolivia: pobreza y concentración del ingreso (línea de pobreza $v s$. índice de Gini)}

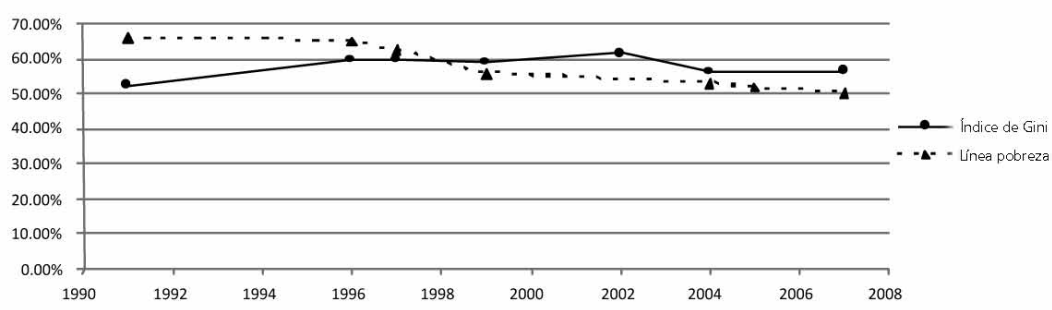

Línea de pobreza: el dato corresponde al porcentaje de la población cuyo ingreso per cápita medio está por debajo de la línea de pobreza. Índice de Gini visto como medida de desigualdad en los ingresos, donde $0 \%$ corresponde a la equidad absoluta y $100 \%$ a la inequidad absoluta. Fuentes: CEPAL, Banco Mundial.

Fuente: Elaborada por Diego Acero, Universidad Nacional de Colombia.

\section{Gráfica VI \\ Brasil: pobreza y concentración del ingreso (línea de pobreza vs. índice de Gini)}

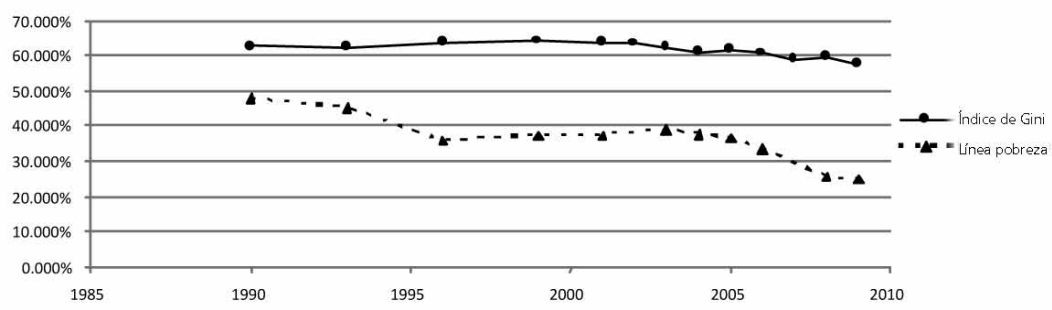

Línea de pobreza: el dato corresponde al porcentaje de la población cuyo ingreso per cápita medio está por debajo de la línea de pobreza. Índice de Gini visto como medida de desigualdad en los ingresos, donde $0 \%$ corresponde a la equidad absoluta y $100 \%$ a la inequidad absoluta. Fuentes: CEPAL, Banco Mundial.

Fuente: Elaborada por Diego Acero, Universidad Nacional de Colombia. 


\section{Gráfica VII \\ Colombia: pobreza y concentración del ingreso (línea de pobreza $v s$. índice de Gini)}

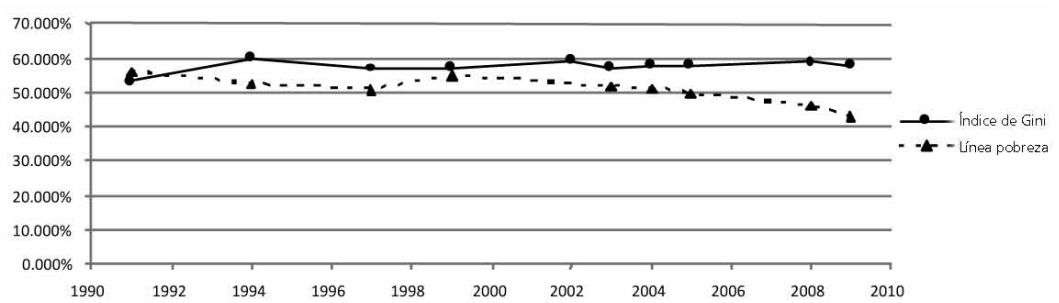

Línea de pobreza: el dato corresponde al porcentaje de la población cuyo ingreso per cápita medio está por debajo de la línea de pobreza. Índice de Gini visto como medida de desigualdad en los ingresos, donde $0 \%$ corresponde a la equidad absoluta y $100 \%$ a la inequidad absoluta. Fuentes: CEPAL, Banco Mundial.

Fuente: Elaborada por Diego Acero, Universidad Nacional de Colombia.

\section{Gráfica VIII \\ México: pobreza y concentración del ingreso (línea de pobreza $v s$. índice de Gini)}

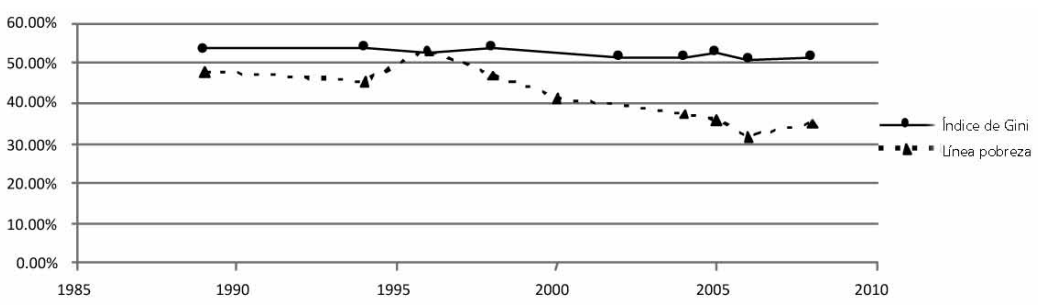

Línea de pobreza: el dato corresponde al porcentaje de la población cuyo ingreso per cápita medio está por debajo de la línea de pobreza. Índice de Gini visto como medida de desigualdad en los ingresos, donde $0 \%$ corresponde a la equidad absoluta y $100 \%$ a la inequidad absoluta. Fuentes: CEPAL, Banco Mundial.

Fuente: Elaborada por Diego Acero, Universidad Nacional de Colombia. 
universal de bienes considerados mínimos para la vivencia de una ciudadanía social, como salud, educación, vivienda, agua potable, servicios públicos domiciliarios y acceso a la justicia. Para tales bienes no debieran existir focalizaciones discriminatorias, porque toda la población, con independencia de su condición, merece su goce por el solo hecho de nacer y vivir. Derechos que deberían ser exigibles y garantizados en cualquier parte del territorio nacional y mańana, cuando seamos sabios, respetados y tengamos garantías en todas partes de América Latina; cuando la focalización es una alternativa a la universalización de los derechos deberá ser rechazada; pero cuando la focalización es el gancho para detectar, atraer y vincular a personas, comunidades y territorios hacia políticas universales, entonces debe ser apoyada. Y cuando la focalización es el medio para atender a personas y grupos excepcionales, que no son bien tratados en su necesidad y especificidad por las políticas y servicios universales, entonces enaltece los principios del humanismo (Ocampo, 2008).

Una última advertencia, obtener los bienes y servicios mínimos puede que disminuya las inequidades, pero no forzosamente las acaba. Es por eso, una vez más, que la prioridad a los grupos más desvalidos no se adopta solamente por un principio de piedad, el cual es suficiente como razón moral y política para hacerlo, sino que se inscribe en un alegato a favor de sociedades más equitativas. De lo contrario, se resbala fácilmente en el asistencialismo y la misericordia, prácticas que no afectan las condiciones que cavan el hueco por el cual se cuelan sin cesar millones de personas en la pobreza y la indignidad.

\section{La representación política de los territorios en la nación}

Hasta ahora los procesos de descentralización política se han concentrado en la transformación de los sistemas electorales locales; ninguno de ellos ha planteado una modificación de la representación política de los territorios en las instancias nacionales del Estado (Restrepo, 2006b; Rivera, 2001). Mientras esto continúe así es improbable que se modifiquen las relaciones políticas que mantienen la alta concentración del gasto estatal y privado en pocas entidades territoriales. El Estado y el mercado dependiente y de enclave que caracteriza a América Latina se recrea a través del sistema político centralizado, el cual compendia en la ficción nacional su carácter mal hecho, incompleto, subordinado y carente de soberanía. La subordinación de la nación a las potencias externas y sus principales grupos económicos es la razón fundamental de la innecesaria difusión del desarrollo en todo el país. La dependencia externa presiona contra una mayor difusión del poder político en la sociedad y los territorios, a cambio de alimentar la centralidad de los grupos con los cuales negocia la 
inserción subordinada al mercado mundial. Finalmente, la centralización y concentración del poder económico y político nacional deviene en colonialismo interno, mediante el cual son sometidas millones de personas y vastos territorios. Quizás entonces el giro de la tuerca que comprime el desarrollo en América Latina podría revertirse interviniendo el mecanismo desde abajo. Es decir, logrando potenciar desarrollo y bienestar de manera más equitativa entre los territorios mediante la ampliación y el fortalecimiento del mercado interno (Becker et al., 2003). De tal manera, se podrían generar condiciones para negociar mejor inserciones múltiples en el mercado mundial. También quizás por esta vía emprendamos la superación definitiva de los experimentos populistas y asistenciales de derecha e izquierda. Unos y otros se legitiman en la necesidad de integración social y territorial negada por el capitalismo de enclave.

Los Estados unitarios, como Colombia, Ecuador, Bolivia y Perú vencieron el federalismo en el siglo XIx. Las grandes formaciones nacionales, como México, Brasil y Argentina, llegaron a ser Estados gracias a la adopción del federalismo; sin embargo, con base en el fortalecimiento del centro y del presidencialismo entre los siglos XIX y XX se entregaron igualmente a la tarea de debilitar los poderes territoriales para construir el Estado-nación durante el siglo xx (Carmagnani, 1993). Los unos y los otros guardan una significativa representación de los territorios internos en los congresos nacionales, combinado con un principio de representación por cantidad de habitantes, que suele primar, en número, a la representación territorial. Al final, las grandes entidades territoriales, que suelen ser las más desarrolladas económicamente, concentran también la mayor representación política (gráfica Ix).

¿Tiene entonces alguna razón volver a plantear la representación política de los territorios en la nación? Quizás adoptar un mayor equilibro entre representación liberal, por número de ciudadanos adultos, y por entidad territorial, construya una mayor equidad en las posibilidades de desarrollo y autonomía entre las regiones de los países. Otro llamado proviene de las contiendas políticas del siglo XIX, aquellas que reintegraron la libertad a la población indígena y negra esclava, más no los derechos políticos de representación. Ahora, a comienzos del siglo XXI no se puede seguir negando la persistencia de la especificidad étnica. Más allá del folclor, la América india y negra demanda reconocimiento como sujetos colectivos de derechos: a la propiedad comunal, a las autoridades propias, las lenguas, códigos de justicia, usos y costumbres, y a la existencia como sujetos políticos colectivos.

América Latina es una sumatoria superpuesta de relaciones sociales y productivas, cada una de ellas con sus agentes, instituciones, racionalidades y representaciones políticas. Quizás ya es hora de reconocer el mesti- 
zaje cultural y político que hemos venido a ser y, en consecuencia, atreverse a crear un sistema de representación que reconozca, respete y combine todo lo que somos. Combinar en proporciones más equilibradas, por tanto, derechos y representación: individual, territorial y comunitaria.

\section{Gráfica IX \\ Concentración de representación política en la nación (territorios principales, cinco elecciones)}

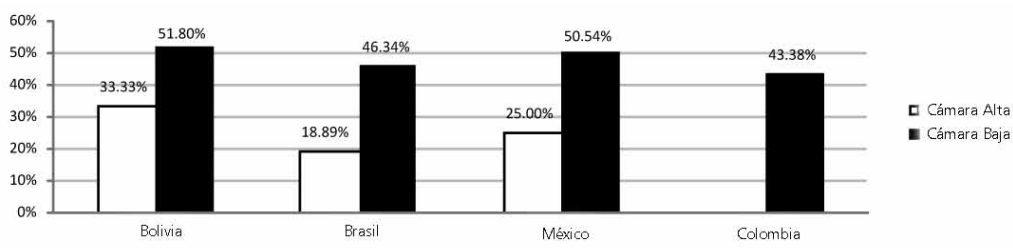

Bolivia: tres de nueve departamentos: La Paz, Santa Cruz y Cochabamba. El dato se refiere a la concentración promedio de la representación política en cinco elecciones (1985 a 2005). Fuente: Centro Nacional Electoral.

Brasil: cinco de 27 unidades federativas: São Paulo, Río de Janeiro, Minas Gerâis, Rio Grande do Sul y Paraná. El dato se refiere a la concentración promedio de la representación política en cinco elecciones (1982 a 2002). Fuente: Secretaría del Tribunal Superior Electoral.

México: ocho de 32 entidades fedetarivas: Distrito Federal, Estado de México, Jalisco, Nuevo León, Veracruz, Guanajuato, Puebla y Chihuahua. Concentración promedio de la representación política en cinco elecciones, para el caso del Senado, y siete elecciones, para el caso de la Cámara de Diputados (1985-2006). Fuente: Cámara de Diputados y Senado de la República.

Colombia: el distrito capital y cinco de 32 departamentos: Bogotá D.C., Antioquia, Valle, Cundinamarca, Santander y Atlántico. A partir de 1991 el Senado (Cámara Alta) se elige en circunscripción nacional, más no territorial. El dato se refiere a la concentración promedio de la representación política en cinco elecciones (1982, 1990, 1998, 2002, 2006) de Cámara de Representantes (Cámara Baja). Fuente: Congreso de la Repúlica.

Fuente: Elaborada por Diego Acero, Universidad Nacional de Colombia.

\section{Bibliografía}

Aghón, Gabriel y Herbert Edling (comps.) (1997), Descentralización fiscal en América Latina: nuevos desafíos y agenda de trabajo, CEPALGTZ, Santiago de Chile.

Aghón, Gabriel (2001), Desarrollo económico y descentralización en América Latina: análisis comparativo, CEPAL-GTZ, Santiago de Chile.

вм (Banco Mundial) (1993), Invertir en salud. Informe sobre el desarrollo mundial, Oxford University Press, Washington. 
вм (Banco Mundial) (2001), Lucha contra la pobreza. Informe sobre el desarrollo mundial 2000/2001, Mundi-Prensa, Madrid.

Bauman, Zygmunt (1998), La globalización. Consecuencias humanas, Fondo de Cultura Económica, Barcelona.

Becker, Alejandro, Sandra Castro y Miguel Eduardo Cárdenas (comps.) (2004), Desarrollo de las regiones y autonomía territorial, GTZFescol, Bogotá.

Becker, Alejandro, Carolina Chica y Miguel Eduardo Cárdenas (comps.) (2003), Ordenamiento territorial. Reivindicación de la descentralización para el desarrollo, Fescol-GTZ, Bogotá.

Benko, Georges y Alian Lipietz (1994), Las regiones que ganan, Edicións Alfons El Magnánim, Valencia.

Burki, Shahid Javed, Guillermo E. Perry y William Dillinger (1999), Más allá del centro: la descentralización del Estado, Banco Mundial, Washington.

Carmagnani, Marcello (coord.) (1993), Federalismos latinoamericanos: México, Brasil, Argentina, Fondo de Cultura Económica, México.

Carreras Serra, Francesc de, Darío I. Restrepo y Alfonso José Roberto Rodríguez (2005), Descentralización en perspectiva comparada. España, Colombia y Brasil, Plural-Friedrich Ebert Stiftung-ILDIs, La Paz.

Carrión, Fernando (ed.) (2003), Procesos de descentralización en la Comunidad Andina, FLACso-oea-Parlamento Andino, Quito.

Castagna Alicia, Isabel Raposo y María L. Woelfin (eds.) (2002), Globalización y territorio, Universidad Nacional de Rosario, Rosario.

Castro, Jaime (2002), La cuestión territorial, Oveja Negra, Bogotá.

Cortés, Pedro, Luis H. Briseño y Darío I. Restrepo (eds.) (2002), Enlaces y rupturas. Experiencias de participación representativas de una década en Colombia, Fundación para la Participación Comunitaria-Acción Ecuménica Sueca-Diakonía, Bogotá. 
Departamento Nacional de Planeación (2003), Lineamientos para el proceso de construcción de un futuro para Colombia desde sus territorios, Corporación Andina de Fomento-Departamento Nacional de Planeación, Bogotá.

Eaton, Kent (2004), Politics beyond the capital: the design of subnational institutions in South America, Stanford University Press, Stanford.

Fals, Orlando (2000), Acción y espacio. Autonomía en la nueva república, Tercer Mundo-Universidad Nacional de Colombia, Bogotá.

Harvey, David (2007), Espacios del capital. Hacia una geografía crítica, Akal, Madrid.

Jessop, Bob (1993), "Towards a schumpeterian workfare state? Preliminary remarks on post-fordist political economy", Studies in Political Economy, 40, Carleton University, Ottawa, pp. 7-40.

Melucci, Alberto (1999), Acción colectiva, vida cotidiana y democracia, El Colegio de México, México.

Misas, Gabriel, Édgar González y Darío I. Restrepo (2005), Desarrollo social y democracia local, Alcaldía de Bogotá-Corporación Escenarios-Oveja Negra, Bogotá.

Molina, Carlos Hugo (coord.) (2008), El movimiento civico frente al proceso de descentralización y autonomía (1994-2006), El País, Santa Cruz, Cochabamba.

Moncayo, Víctor Manuel (1990), El Leviatán derrotado. Reflexiones sobre la teoría del Estado y el caso colombiano, Universidad Nacional de Colombia, Bogotá.

Montañés, Gustavo (coord.) (2001), Espacio y territorios. Razón, pasión e imaginarios, Universidad Nacional de Colombia. Bogotá.

Ocampo, José Antonio (coord.) (2002), Globalización y territorio, CEPAL, Santiago de Chile.

Ocampo, José Antonio (2008), "Las concepciones de la política social: universalismo versus focalización", Nueva Sociedad, 215, Friedrich Ebert Stiftung, Buenos Aires, pp. 36-71. 
Pradilla-Cobos, Emilio (2010), Los territorios del neoliberalismo en América Latina, Miguel Ángel Porrúa, México.

Restrepo, Darío I. (2001), "Dimensión espacial y política de la reestructuración capitalista", Economía, Sociedad y Territorio, III (9), El Colegio Mexiquense, Zinacantepec, pp. 93-126.

Restrepo, Darío I. (ed.) (2003), La falacia neoliberal, críticas y alternativas, Universidad Nacional de Colombia, Bogotá.

Restrepo, Darío I. (ed.) (2006), Historias de descentralización. Transformaciones del régimen politico y cambio en el modelo de desarrollo. América Latina, Europa y EUA, Universidad Nacional de Colombia, Bogotá.

Restrepo, Darío I. (2006b), "Las fracturas del Estado en América Latina”, en Darío I. Restrepo (ed.), Historias de descentralización. Transformaciones del régimen politico y cambio en el modelo de desarrollo. América Latina, Europa y EUA, Universidad Nacional de Colombia, Bogotá, pp. 25-52.

Restrepo, Darío I. (ed.) (2007a), Equidad y salud. Debates para la acción, Universidad Nacional de Colombia-Secretaría Distrital de Salud, Bogotá.

Restrepo, Darío I. (ed.) (2007b), 20 años de la descentralización en Colombia: presente y futuro, Red de Iniciativas para la Gobernabilidad, la Democracia y el Desarrollo Territorial, Bogotá.

Revista Nueva Sociedad (2008), Entre macroeconomía y politica social, 215, Friedrich Ebert Stiftung, Buenos Aires.

Rincón, Patricia, Édgar Duarte y Pedro Andrés Héndez (eds.) (2005), Las ciudades-región en el nuevo sistema económico internacional, una mirada desde la integración andina, Alcaldía Mayor de BogotáUniversidad Nacional de Colombia, Bogotá.

Rivera, Rodrigo (2001), Hacia un nuevo federalismo para Colombia, Oveja Negra, Bogotá.

Rodríguez, Óscar (ed.) (2002), Los avatares del servicio de salud para pobres, t. II, Universidad Nacional de Colombia, Bogotá. 
Seoane, José, Emilio Taddei y Clara Algranati (2006), "Las nuevas configuraciones de los movimientos populares en América Latina", en Atilio A. Borón y Gladys Lechini (coords.), Política y movimientos sociales en un mundo hegemónico. Lecciones desde África, Asia y América Latina, Clacso, Buenos Aires, pp. 227-250.

Sousa-Santos, Boaventura de (2003), Democracia y participación: el ejemplo del presupuesto participativo de Porto Alegre, El Viejo Topo, Madrid.

Stiglitz, Joseph E. (2002), El malestar en la globalización, Taurus, Bogotá.

Toranzo, Carlos (1999), Las paradojas de la participación. ¿Más Estado o más sociedad?, Diakonia-Oxfam, La Paz.

Torres-Ribeiro, Ana Clara, Hermes Magalhaes Tavares, Jorge Natal y Rosélia Piquet (eds.) (2005), Globalización y territorio. Ajustes periféricos, Red Iberoamericana de Investigación en Globalización y Territorio-IPuUR-Prolam-Anpur-Arquímedes Ediçoes, Río de Janeiro.

Wiesner-Durán, Eduardo (1992), Colombia: descentralización y federalismo fiscal, Departamento Nacional de Planeación-Presidencia de la República, Bogotá.

Recibido: 3 de julio de 2008. Reenviado: 8 de abril de 2011 . Aceptado: 21 de junio de 2011.

Darío I. Restrepo. Filósofo y especialista en desarrollo por la Universidad Católica de Lovaina, Bélgica. Desde 1987 es profesor en la Facultad de Ciencias Económicas de la Universidad Nacional de Colombia. Investigador del Grupo de Protección Social del Centro de Investigaciones para el Desarrollo en la misma universidad. Actualmente es candidato a doctor en historia en la Facultad de Ciencias Humanas de la Universidad Nacional de Colombia. Entre sus publicaciones recientes se encuentran: editor, Equidady salud. Debates para la acción, Universidad Nacional de ColombiaSecretaría de Salud de Bogotá, Bogotá (2007); "El eslabón perdido de la descentralización en América Latina”, en Fernando Carrión M. y Brigitta Villaronga W. (comps.), Descentralizar: un derrotero a seguir, FLACsoInWEnt-Senplades, Quito, pp. 289-300 (2008); en coautoría, Las entidades 
territoriales en la realización de derechos de la población desplazada, Consultoría para los Derechos Humanos y el Desplazamiento, Bogotá (2009); en coautoría, "Hacia una protección social universal en Colombia", en Aurelio Suárez Montoya y Miguel Eduardo Cárdenas (coords.), Bases de una politica económica para la productividad, el empleo y la distribución del ingreso, Fescol, Bogotá, pp. 121-136 (2009); editor, Inequidad social en salud. El caso de Bogotá, Universidad Nacional de Colombia-Secretaría Distrital de Salud, Bogotá (2010). 